\title{
THE INTERSECTION OF THEORY AND PRACTICE IN TEACHER PREPARATION COURSE
}

\author{
Brandon Juarez, Grand Canyon University
}

\begin{abstract}
The high percentage of new teachers who leave the profession within the first five years of teaching motivated the teacher educator to consider an alternative path to andragogically approaching course content. Thus, the teacher educator grappled with the process of transitioning theories of the content to application-based andragogy. The intersection of theory and practice came to fruition in one teacher preparation course. To this end, the teacher educator set out to foster a learning environment that yielded safety and trust for pre-service teacher candidates to participate in simulations throughout class sessions. In this summary, the teacher educator illuminates innovative and practical teaching practices, solutions to overcoming obstacles, and how this approach can be utilized in other curriculum and content areas.

Keywords: andragogy, application-based teaching, simulations

According to the most recent data from the US Department of Education, nearly half of all new teachers leave the profession by their fifth year of teaching. Amid increased attention placed on the teaching profession (Kumashiro, 2015), there appears to be disconnect between the andragogy within teacher preparation instruction and the teaching profession. Specific to the field of teacher preparation, there are a plethora of websites, articles, and online resources aimed to offer support to novice or entry-level teachers. Thus, with the stark statistics of teacher attrition and the subsequent available resources offered to this population, one can assume a gap between how pre-service teacher candidates are being taught and what they apply to their new profession. This summary explores the practice of using simulations, scenarios, and role-playing to teach course content that is closely aligned to the teaching profession. Throughout this paper, the author is the researcher and teacher educator to the particular class environment outlined below. Consequently, the terms researcher and teacher educator will be used interchangeably. Attention is paid to specific types of application-based andragogy as well as preparing the faculty member to implement application-based instruction. Salomon

and Perkins (1989) transfer of learning theory is used to explore how transferring course content to application-based andragogy is applied in this context. To this end, the researcher of this paper targets the teacher preparation field but provides descriptions and details in an attempt to appeal to a broader audience within higher education.

Application-based andragogy is the instructional practice of using real-world scenarios or simulations as means to engage students (in this case, pre-service teacher candidates). This practice aligns to Dewey's work with respect to Constructivism and the importance of applied learning (Vanderstraeten, 2002). In the sections to follow, the researcher will unpack the lens through which application-based andragogy is constructed, when this mode of instructional practice is most needed, and how to overcome obstacles in the development of this practice. Throughout the paper, the reader will be provided various strategies to assist in the much needed practical experiences to teacher preparation courses. The researcher will conclude the paper with recommendations for future applications of this instructional practice as well as suggestions for implementation.
\end{abstract}




\section{INNOVATIVE AND PRACTICAL TEACHING PRACTICES}

Particular subjects or course content are easier to transition to application-based andragogy than others. Subsequently, the critical question the teacher educator or faculty member should ask is: "can students (in this paper, pre-service teacher candidates) practice this content in a simulated environment"? In the realm of teacher education, classroom management is a critical skill all teachers implement (to varying degrees of necessity and merit). A classroom management course, within a teacher preparation program, was the course used to conduct application-based andragogy. Of the nearly 25,000 teacher preparation programs (Kumashiro, 2015) across the US, classroom management is widely accepted as a critical course pre-service teacher candidates take within their degree program. The practicality of the content lends to application-based andragogy because preservice teacher candidates have the opportunity to rehearse how to respond or react to their future students. Therefore, based on the national statistic cited above, the reader could draw the conclusion teacher preparation programs are insufficiently preparing pre-service teacher candidates for the reality of the profession.

\section{Simulations}

In-class simulations provide opportunities for pre-service teacher candidates to role play possible student interactions and class situations. Salomon and Perkins (1989) highlighted high-road and low-road of transfer are critical constructs to transferring skills in new situations. Therefore, in the scope of this classroom management course, a supreme focus was placed on providing enough practical opportunities for pre-service teacher candidates to role-play potential situations to allow for subconscious transfer of skills to mature. Thus, simulations dominated the learning time and space throughout the course. Highlighted below, further explanation is provided regarding how to arrange the class and prepare pre-service teacher candidates for routine and structured simulations. The intention is to provide detail regarding how arrangements were made to garner interest and willingness to participate.

\section{Scenarios}

Each class session throughout the term included mock scenarios for the pre-service teacher candidates to explore. The researcher had taught this particular course for five years (each Spring semester/term) with several class sections each semester. Subsequently, the researcher was comfortable with the content curriculum and had slowly implemented application-based andragogy each semester. Moreover, the high frequency of positive End of Course feedback and comments further encouraged the researcher to implement this practice. Pre-service teacher candidates were provided flexibility to solve scenarios independently or in small groups. Regardless of format, preservice teacher candidates were expected to justify and reason for their approach to solving the scenario in the latter portion of the class session. The focus here was not the content of the scenarios, but rather the high frequency of using scenarios to allow for implementation of what they learned from the course content. In essence, once a description of the learning experience was provided and preservice teacher candidates recognized the inherit value of the learning experience, the andragogical practice became authentic and applicable.

\section{OVERCOMING HURDLES AND SOLUTIONS TO THE OBSTACLES}

In many cases, pre-service teacher candidates did not initially demonstrate a desire to participate in simulations, role playing, and scenarios. There were reservations among pre-service teacher candidates with fear of looking silly, not knowing how to respond to the prompts provided, and responding to the situations incorrectly. The teacher educator overcame these obstacles in three ways. First, simulations (including role playing and scenarios) started after several weeks of fostering rapport with students. Each class session leading up to the start of simulations, the teacher educator used an icebreaker to promote pre-service teacher educators becoming comfortable with each other and the class environment. In the spirit of developing rapport and familiarity among peers, the teacher educator deployed frequent instructional strategies to group pre-service teacher educators in new and unique ways. Although they did not voice their opinions, the teacher educator keenly explained the purpose of each learning experience in an effort to receive buy-in and offered continuous encouragement throughout the development of these icebreakers and learning experiences. 
Next, the teacher educator made an effort to model the role playing before pre-service teacher educators were expected to participate. Hollins, Luna, and Lopez (2014) highlighted teaching practices among teacher educators and K12 teachers are not perfect substitutes. However, McDonald, Kazemi, and Kavanagh (2013) mentioned there are core teaching principles shared between the two professions. Subsequently, the teacher educator leaned on prior pedagogical strategies to theatrically model how to solve the given scenario. It is important to note, the teacher educator modeled the same scenario in two distinct ways. First, the teacher educator made mistakes and responded to the scenario incorrectly. After the role play, the teacher educator provided time for pre-service teacher educators to talk in small groups to discuss their observations. Next, the teacher educator replayed the same scenario but with the pre-service teacher educators' feedback. This second attempt provided the opportunity to see their input in action, which helped develop confidence later in the course when they were given the opportunity to role play and simulate the scenario on their own. The second (or third attempt, if necessary) produced the correct response and provided subsequent discussion after the learning experience.

The final obstacle in this practical teaching practice was getting pre-service teacher educators to participate. With the potential apprehension in mind, the teacher educator sent electronic messages days before the class simulation requesting pending participation. Or, the teacher educator pulled pre-service teacher educators aside before the start of each lesson to ask for participation. This process provided time to prepare for the learning experience. Regardless of style of requesting participation, the teacher educator first asked preservice teacher educators who were either willing to volunteer or with whom there was a strong developed rapport with the teacher educator. Moreover, in an effort not to place individual preservice teacher educators on the spot, the teacher educator created the environment for multiple role playing simulations to take place concurrently. This way, they were less likely to be embarrassed. Overall, by starting slow and specifically targeting individual pre-service teacher educators (first) who were more willing than others, the teacher educator was able to build momentum of participation among the full class roster.

\section{FUTURE APPLICATION AND SUGGESTIONS FOR IMPLEMENTATION}

Although many content-specific courses for pre-service teacher candidates lend to applicationbased andragogy, the main takeaway from this experience was the ability to apply this strategy to other content areas. The teacher educator learned the process largely hinged on self-confidence and rapport building with higher education students. As Juarez (2019) highlighted, teacher educators often refer to K12 practices in their andragogical practices and the process is justified because the teacher educator is teaching future K12 teachers who can apply the modeling to their own future teaching practices. Thus, the cyclical nature of the instructional process is validated. To this end, the teacher educator in this paper had to first overcome the notion of impractical and nuanced differences between pedagogical and andragogical strategies. Rather, blending the two strategies provided a bridge for the teacher educator to connect the course content to future pedagogical practices for the pre-service teacher candidates.

Another suggestion for future implementation is to begin the term with routine opportunities for students to collaborate and learn about and with each other (regardless if students are specifically pre-service teacher educators). The environment the teacher educator (or faculty member) creates for students or pre-service teacher educators is just as valued as the application-based teaching strategies used throughout the term. For example, there are a plethora of online icebreaker activities the teacher educator or faculty member can use to promote engage and interactions. The value is the interaction, not necessarily the specific activity. Moreover, as the term begins, there should be a gradual shift to application-based andragogy. Thus, frequency of application-based instruction is the key. Starting the process of interacting with each other lays the foundation for familiarity and comfort when the teacher educator or faculty member advocates and leads students to trying an uncomfortable learning experience or activity.

\section{CONCLUSION}

The scathing literature regarding the high- 
level of turnover in the teaching profession paved the way for this teacher educator to investigate andragogical strategies that would best prepare preservice teacher candidates for their futures. These pre-service teacher educators needed practice and repetition to foster their classroom management skills. Moreover, the teacher educator used transfer or learning theory (Salomon \& Perkins, 1989) to amalgamate direct instruction and applicationbased instruction to provide in-class simulations for pre-service teacher candidates. The process of developing a safe learning experience for preservice teacher educators along with routinely fostering student interactions and collaboration with peers proved to affirm the use of role playing, simulations, and scenarios as best practices for pre-service teacher candidates. Overall, the teacher educator embarked on this process slowly. Over time, pre-service teacher educators as well as the teacher educator became comfortable with the experiences. 


\section{REFERENCES}

Hollins, E., Luna, C., \& Lopez, S. (2014) Learning to teach teachers. Teaching Education, 25:1, p. 99-124, doi: 10.1080/10476210.2012.755956

Juarez, B. C. (2019). Online teacher educators transitioning teaching practices to the face-to-face modality (Order No. 13898937). Available from Dissertations \& Theses @ Grand Canyon University; ProQuest Dissertations \& Theses Global. (2247120490). Retrieved from https://lopes.idm.oclc.org/ login?url=https://search-proquest-com.lopes.idm.oclc.org/doc view/2247120490?accountid=7374

Kumashiro, K. (2015). Review of proposed 2015 federal teacher preparation regulations. National Education Policy Center. Retrieved from http://nepc.colorado.edu/thinktank/reviewproposed-teacher-preparation

McDonald, M., Kazemi, E., \& Kavanagh, S. S. (2013). Core practices and pedagogies of teacher education: A call for a common language and collective activity. Journal of Teacher Education, 64(5), p. 378-386. Retrieved from http://journals.sagepub.com.lopes.idm.oclc.org/doi/ pdf/10.1177/0022487113493807

Salomon, G. \& Perkins, D. N. (1989). Rocky roads to transfer: Rethinking mechanisms of a neglected phenomenon. Educational Psychologist, 24(2), p. 113-142. Retrieved from https://lopes.idm.oclc.org/login?url=http://search.ebscohost. com/login.aspx?direct=true\&db=edswss\&AN=A1989AD5460 0001\&site=eds-live \&scope $=$ site

Vanderstraeten, R. (2002). Dewey's transactional constructivism. Journal of Philosophy of Education, 36(2), 233. https://doiorg.lopes.idm.oclc.org/10.1111/1467-9752.00272 